Check for updates

1 Chair of the UK Health Alliance on Climate Change

Cite this as: $B M J$ 2021;375:n2728 http://dx.doi.org/10.1136/bmj.n2728 Published: 08 November 2021

\section{COP26 diary: making health central to tackling climate change}

\author{
Richard Smith reports from COP26 in Glasgow \\ Richard Smith
}

\section{Thoughts on travelling to COP26}

On the train from Euston for COP26 in Glasgow I imagine myself to be Perseus about to rescue Andromeda from the sea monster, as wonderfully depicted in Titian's painting. Then I reflect that that's an unacceptably sexist image for 2021. Life is more complicated now. Still it won't be long before I'm “cancelled." I used to think that I would be cancelled before the impact of climate change hit, but it's here now-and is set to get exponentially worse in the 20 years I could have left.

COP26 is billed as "the world's last chance," and I find it intriguing, even amusing, that our future should be decided in that Victorian, but industrially-scarred jewel. I imagine Billy Connolly cracking jokes as we sink beneath the waves. COPs are like other international institutions-weak, politicised, and prone to "sound and fury signifying nothing," but they are the best we have. That's why, cynical and disillusioned as we might be, I still make the pilgrimage to the jamboree, not least to catch up with old friends.

I go wearing my hat as chair of the UK Health Alliance on Climate Change, an alliance of most of the health colleges and other leading health organisations. Others on the train look like weary delegates wondering why they have to travel to the edge of Europe to save the planet. I have to give four talks in Glasgow and co-host a dinner for health leaders. I find it hard to believe that my presence and contribution will make much difference, but that's not the point. "Better," says Einstein on a million tee-shirts, "to light a candle than live in darkness." But in darkness, I muse, you can see the stars.

The Alliance has joined the chorus insisting that we do everything we can to keep global temperature increase below 1.5C above pre-industrial levels. The Chinese say that is not possible, and we know that they are right. But we stick to the mantra and struggle fearing that abandoning them could lead to the climate spiralling out of any control. I have friends who work now on how to respond when things get very bad, probably at the time when my grandchildren reach adulthood and I totter towards the grave. Death doesn't bother me, but I hate that I will die knowing that the planet is wrecked, that I made a substantial contribution to the wrecking, and that my grandchildrens' future is ruined.

That's why I'm on the train to Glasgow, and the sun is shining as we enter the beauties of the Lake District.

\section{Day 1: into the Blue Zone, close to the inner sanctum}

My first day at COP26 is a jolly one, a dinner with other health professionals concerned about climate change, some of whom I know and some of whom I meet for the first time. I meet an emergency department physician from the far north of Canada, over a thousand miles away from a hospital with the full range of services. The indigenous people who constitute most of the population live by hunting and have noticed great changes from climate change.

Another colleague works on climate change in the American government and has seen huge changes since Biden came to power. The Democrats have just lost a key election in Virginia, signalling that next year's midterms may give the Republicans more power and make countering climate change harder. We have a discussion about why climate change is deeply politicised in the US and Australia, but not Britain. We think it's something to do with Zac Goldsmith, a Tory with long-standing concerns about the environment.

I learn as well about medical societies coming together in the US to counter climate change. Surveys show that their members accept it, but, as in Britain, it's taking clinicians longer to recognise that their clinical practice will have to change if we are ever to reach net-zero in health systems.

As I leave I see that Greta Thunberg has tweeted that COP26 is the most excluding of COPs and that it's nothing more than a greenwashing festival for Northern countries.

Accommodation is hard to come by in Glasgow. People are paying $£_{500}$ a night for hotel rooms. Others have had their bookings of a year ago cancelled because owners can get higher sums now. Many are commuting from Edinburgh. I'm lucky in that my sister-in-law lives 20 miles North-West of Glasgow on the Firth of Clyde. COP26 has impinged on her and her partner by making journeys in and out of Glasgow more difficult.

There is a climate change angle to where I'm staying in that it's a newly built house, and Scottish regulations insist that new houses must have heat-pumps, not gas boilers fitted. I'm shown the heat pump: it's big outside and very complex inside. Heat pumps are expensive, but a bigger problem is that there are limited numbers of people with the skills to fit them. My sister-in-law's heat pump had teething problems, and it was hard to find somebody to fix them.

There are some 25 million homes in Britain that are going to have to have heat pumps fitted over the next 
20 years if we are to reach net zero by 2050 (10 years too late, the UK Health Alliance in Climate Changes says). There's a need for tens of thousands of skilled workers. These will be well paid jobs, but we will need a rapid increase in training capacity.

My sleep is troubled by the complications of having to do and register a lateral flow test for covid-19 in order to be admitted to COP26. If I get it wrong I'll not be admitted, not make my talk, and will have wasted my journey. My anxiety is compounded by the thought that it might take me hours to get into $\mathrm{COP} 26$ and so must leave very early.

I'm up soon after 6am making tea and doing my lateral flow test. It is, as I expected, negative, and I register it with the NHS. It would, I reflect, be very easy to cheat. I'm on the train by $7.25 \mathrm{am}$ and am privileged to see a fiery sunrise over Glasgow. When I get off at the Exhibition Centre soon after 8am I discover that I'm part of a large crowd flowing towards $\mathrm{COP} 26$. As I always do when part of a flowing crowd I think of T S Eliot's line borrowed from Dante, "I never knew death had undone so many.” At the same time I wonder what all these people are doing. Why does COP26 need so many people?

The first hurdle to entry is simply to show my negative test. Next I must show my passport. Then I enter a large queue waiting to move through airport-style security, but suddenly we all move through. Now I must get my badge. I never have to show my evidence that I've been doubly vaccinated. It all seems easy, perhaps too easy. I see a tweet from Trish Greenhalgh that $\mathrm{COP} 26$ will prove to be a superspreader event.

After much more walking I enter an area where some 80 pavilions are contained. Each is a little empire with screens showing expensive videos, chairs, coffee, posters, and various embellishments. Some belong to countries, others to movements, groups, and funds. You get what you pay for, and some have a second floor. The fanciest have a barista. The effect is corporate and bewildering. I remain bewildered for most of the day. I'm reminded of the World Heart Meeting and the World Economic Forum.

I find my way to the Health Pavilion, which is relatively modest. Nobody is there. Our session is not until 10am. I set off to find coffee and, I hope, a bacon roll. There are lots of places selling coffee and goodies, but already the queues are long. I get my coffee and a sandwich (no bacon roll available), find a seat, and remove my mask. We must wear masks unless eating or speaking to an audience. As the day progresses, seats become harder to find despite there being hundreds.

Back at the Health Pavilion people are beginning to gather, some of whom I know. I'm seeing people in person that I've only ever seen on screen. Some are taller than I expected, some shorter. Our session begins at 10. There are two of us here in person and six, including the chair, online. The audience are all masked and listening on headphones so as not to drown out other pavilions. Most have phones or laptops. Are they, I wonder, listening to us or looking at something more interesting on Instagram? Despite the almost mandatory technical hitch, the session goes well. I learn that the carbon footprint of a cataract operation done by Aravind in India is $5 \%$ of one done in the UK, showing what huge room there is for improvement. Aravind achieves such a low footprint by seeing patients only once, avoiding travel, reusing gowns, gloves, and equipment, and keeping waste to an absolute minimum. Surgeons do seven operations an hour, and infection rates are lower than in Britain.

After that session I walk perhaps a third of a mile to a meeting room, marvelling at the scale and complexity of the conference. As I walk
I pass crowds of people going in both directions. I'm reminded of herds of reindeer on the Russian steppes. There's a feeling that most people at the meeting are on the move, heading who knows where.

The meeting I'm attending is an advocacy meeting of health people trying to make health more central to negotiations over climate change. There is universal praise and admiration for Rita Issa, a doctor who has had the courage and quickness of mind to make a strong statement about the need to make health central to tackling the climate emergency directly to Alok Sharma, the COP26 president. I'm also mightily impressed by the medical students who are knocking on the doors of the offices of the delegates and asking to talk about the importance of health. Most delegates have welcomed them, although the Chinese have rebuffed them. There is also a discussion about giving negotiators, the key people at COP26, a piece of paper with words about health that might be included in the final statement from $\mathrm{COP}_{2} 6$.

The health voice is coming through more clearly at this COP and in discussions over climate change and environmental destruction generally. The World Health Organisation (WHO) has a pavilion for the first time. Health will feature briefly in the negotiations. The New York Times, probably the world's most influential newspaper, has published a long piece on the rising voice of health, and Issa and the medical students have bravely advanced health in the minds of negotiators.

After our meeting I go to look at NHS England's carbon-zero ambulance, which is driven by electricity and hydrogen. In cities, electricity might be enough, but in places where ambulances have to cover large distances, hydrogen may be needed. The paramedic who describes the ambulance to me says how it has been assembled by several different companies for $\mathrm{COP} 26$. It's not yet in service, but it will be once it has passed final checks. It strikes me as a particularly "comfortable" ambulance-if that's a word that can ever be used about ambulances.

I go in search of food, passing through restaurants the size of aircraft hangers serving among many other dishes "haggis, neaps, and tattles." I'd be interested to know if they get many takers. I opt for some vegetarian scotch broth and go outside to eat. I fall into conversation with a German woman whose main interest is agriculture and food. We get to talking about death and how we die is linked with climate change and the pandemic in that they all arise from our delusion that we are masters of nature, not part of nature.

Back in the hall I hear a man arguing in the Nordic Countries' pavilion that nature and biodiversity are still not getting the attention of climate change. Half of the world's economy depends on nature (mostly exploiting it unfortunately), and if nature goes we go. We are part of nature. In the Cryosphere Pavilion, I hear an impassioned plea for oceans from an intensive care doctor. The Earth, he points out, is misnamed in that $70 \%$ of the planet is ocean. The oceans give us food, oxygen, transport, medicines, energy, cooling, and carbon sequestration, but we are progressively destroying them. "No blue, no green, no life," he explains, emphasising the short timescale. Many NHS supplies arrive by sea, but at the same time the NHS is making a big contribution to damaging the ocean. He wants the oceans to have a voice. I make a mental note to invite him to give a webinar for the UK Health Alliance on Climate Change.

Now to the die-in, eight medical students in scrubs lying dead on the floor. Die-ins have become popular. They make a good photo opportunity. The more corpses the better. I've participated in one before, and it can be surprisingly relaxing, lying on the floor, pretending to be dead, and listening to the hubbub around you. 
Other students are behind a banner calling for an end to fossil fuels, and two students make speeches. There is then some chanting.

I find myself wondering why I am here at COP26, and I discuss the question with a friend who has been to many COPs. You need to have an objective, he tells me: are you here to advocate, learn, be energised, perform, or make contacts, seek collaborations? I suppose it's a combination of all of those objectives, but I should probably be more specific if I attend another $\mathrm{COP} 26$.

People are now streaming out of $\mathrm{COP} 26$. I meet a medical student friend, and he takes me to a pub disguised as a church with an open fire (attractive and warming, but bad for air pollution and the climate), where we eat vegan food (good). I find it comforting to be in this old and largely empty room after the frenzy of COP.

Competing interests: Richard Smith is the chair of the UKHACC and is a former editor-in-chief of The BMJ.

Provenance and peer review: Commissioned, not peer reviewed

1 https://www.nytimes.com/2021/11/04/climate/public-health-climate-change.html 